\title{
Operating-point insensitive voltage control of the Z-source inverter based on an indirect capacitor current control
}

ISSN 1755-4535

Received on 16th July 2014 Revised on 17th December 2014 Accepted on 16th January 2015 doi: 10.1049/iet-pel.2014.0463 www.ietdl.org

\author{
Kwang-Woon Lee ${ }^{1}$, Taehyung Kim ${ }^{2} \bowtie$ \\ ${ }^{1}$ Department of Electronic Engineering, Mokpo National Maritime University, Mokpo, Jeollanam-Do, Republic of Korea \\ ${ }^{2}$ Department of Electrical and Computer Engineering, University of Michigan - Dearborn, Dearborn, MI 48128, USA \\ 凶E-mail: taehyung@umich.edu
}

\begin{abstract}
This study presents a novel design strategy for the capacitor voltage control of a Z-source inverter (ZSI) to overcome the complexity and control performance degradation involved with the conventional small-signal modelbased controls. In the proposed approach, the Z-network capacitor voltage of the ZSI is controlled through the average capacitor current over a switching period, and thus, the dynamics of the Z-network capacitor voltage can be easily controlled. To make this happen, the average capacitor current model is derived based on an important finding that the average capacitor current can be indirectly controlled through the average Z-network inductor current. For the inner Z-network inductor current control, the average voltage model of the inductor is developed to control the average inductor voltage directly via the shoot-through duty ratio of the ZSI. In this way, the current control dynamics can be linearised over an entire operating range and the desired bandwidth of each controller can be simply obtained using only Z-network parameters without a gain tuning process unlike the small-signal model-based controls. Thus, the proposed method can simplify the design process while producing an excellent control performance. The simulation and experimental results verify that the transient responses exactly coincide with the desired design goal.
\end{abstract}

\section{Introduction}

The Z-source inverter (ZSI), comprised of an X-shaped impedance network called as the Z-network and a conventional 3-phase voltage source inverter (VSI), has attractive features such as an input voltage boosting capability and improved reliability [1,2]. It intentionally makes the shoot-though (ST) state during the zero voltage vector applying period of the VSI to supply currents to the Z-network inductors. The Z-network capacitors are charged by the Z-network inductor current during the non-shoot-through (NST) state. These basic operating modes of the ZSI lead to the boosting of the inverter dc-link voltage. There has been a lot of research to utilise the intrinsic features of the ZSI, gaining significant attention in renewable energy generation applications, such as fuel cells and photovoltaic arrays [3-7].

When the Z-network inductor current is equal to or less than half of the inverter dc side current, the ZSI operates in the unwanted operation modes where the inverter dc-link voltage is distorted and the performance of the inverter is also degraded [8]. To guarantee stable operation of the ZSI, the parameters of the Z-network should be chosen carefully and the load power factor of the inverter should be controlled properly $[8,9]$. The ac output voltage control performance of the ZSI is closely related to the amplitude of the dc-link voltage during the NST state so that the feedback control of the dc-link voltage is essentially required. The dc-link voltage response is directly influenced by the current and voltage responses of the Z-network and small-signal models have been generally used for the operation analysis and control of the Z-network [10-14]. To obtain a stable operation of the ZSI, the dual-loop control consisting of the inner current control loop and outer voltage control loop is usually preferred [13].

The conventional design process for the ZSI control can be summarised in the following steps [10-14]: (i) the state equations of the ZSI are considered and ac small signal models based on state space averaging are derived; (ii) the controlto-inductor-current and inductor-current-to-capacitor-voltage transfer functions of the ZSI are developed from the derived ac small signal models. It should be noted that the transfer functions of the ZSI derived at this stage are totally reliant on the steady state values of the state and input variables of the ZSI at a specific operating point; (iii) the current controller is designed in the frequency domain; the bode plot of the open loop transfer function including the current controller and control-to-inductor-current transfer function is used to select control gains satisfying both the desired bandwidth and phase margin; (iv) the voltage controller is designed in a similar way as is the current controller design.

The performance of the conventional small signal models based ZSI control is only satisfactory when the ZSI operates under a specific operating point, where the transfer functions used in designing controllers are derived. It should be emphasised that a large deviation from the specific operating point can cause a considerable performance degradation of the small signal models based ZSI control. For this reason, another control approach is required to overcome the drawbacks of the conventional small signal models based control.

The purpose of this paper is to present a novel design strategy for the capacitor voltage control of the ZSI to overcome the drawbacks of the conventional small signal models based control. In the proposed method, the current and voltage controllers are designed on the basis of a state space averaging. The average Z-network capacitor current model is introduced to show that the average capacitor current can be indirectly controlled through the average Z-network inductor current. Based on this concept, the capacitor voltage is controlled through the indirect capacitor current control; it gives a linearised transfer function to the capacitor voltage control, and thus, the capacitor voltage controller can be easily designed. From the average voltage model of the Z-network inductor, it is derived that the Z-network inductor's average voltage can be directly controlled through the ST duty ratio; from this, a linearised inductor-voltage-to-inductor-current transfer function, represents the dynamics of the inductor current over an entire operating range except for unwanted modes, is obtained and the current controller design process is greatly simplified. 

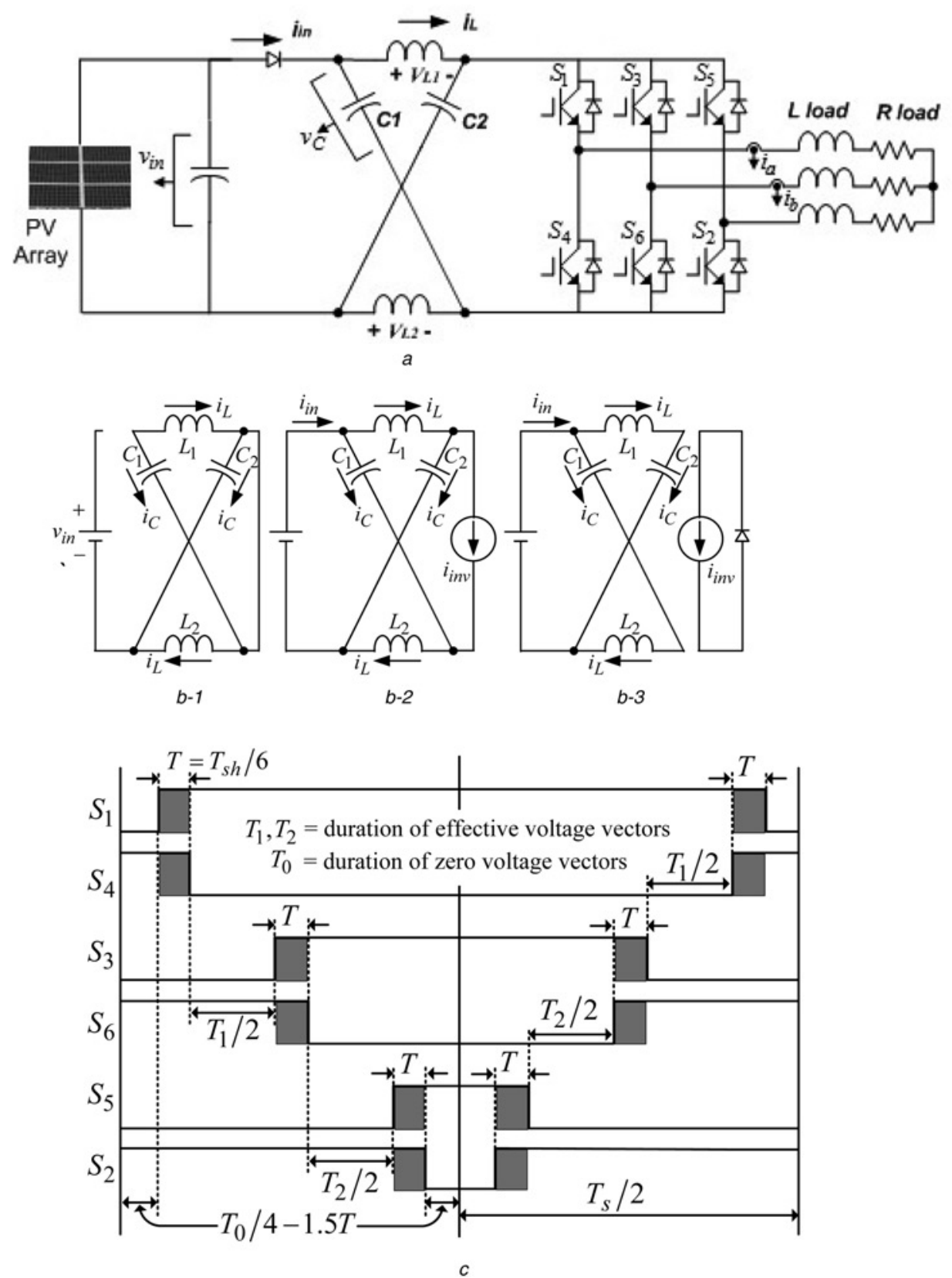

Fig. 1 Basic structure, equivalent circuits and PWM pattern of the ZSI

$a$ Basic structure of the ZSI

$b-1$ Equivalent circuit of the ZSI during the ST state

$b-2$ Equivalent circuit of the ZSI during the NST state when effective voltage vectors are applied to the inverter load

$b$-3 Equivalent circuit of the ZSI during the NST state when zero voltage vectors are applied to the inverter load

$c$ PWM pattern of MSVMBC [18]

In the proposed method, the gains for the outer and the inner control loops are selected by using only Z-network parameters and desired bandwidths. The simulation and experimental studies have been performed to verify that the transient responses of the current and voltage controllers exactly coincide with the desired design goal.

\section{Operations of the ZSI}

The ZSI consists of the Z-network and VSI as shown in Fig. 1 $a$ [3]. The equivalent circuits viewed from the inverter dc-link are shown in Fig. $1 b$; it is assumed that the inductor current, $i_{L}$, is greater than half of the inverter dc-side current, $i_{\text {inv }}$, so that the unwanted modes will not occur [8]. Assuming that the Z-network is symmetrical $\left(L_{1}=L_{2}\right.$ $=L$ and $\left.C_{1}=C_{2}=C\right)$, the inductor voltages and the capacitor voltages are given by

$$
v_{L 1}=v_{L 2}=v_{L}, \quad v_{\mathrm{C} 1}=v_{\mathrm{C} 2}=v_{\mathrm{C}}
$$

During the ST state, as depicted in Fig. $1 b$-1, the capacitor current, $i_{\mathrm{C}}$ and the inductor voltage, $v_{L}$, are given by

$$
\begin{gathered}
i_{\mathrm{C}}=-i_{L} \\
v_{L}=v_{\mathrm{C}}
\end{gathered}
$$

During the NST state, there are two equivalent circuits: one is for the effective voltage vector period and the other for the zero voltage 
vector period. The inductor voltage during the NST state is given by

$$
v_{L}=v_{\text {in }}-v_{\mathrm{C}}
$$

where $v_{\text {in }}$ is the input voltage of the ZSI. During the NST state, $i_{\mathrm{C}}$ varies depending on the operating mode of the inverter. In Fig. $1 b-2, i_{\mathrm{C}}$ is expressed by

$$
i_{\mathrm{C}}=\left(i_{L}-i_{\text {inv }}\right)
$$

In Fig. $1 b-3, i_{\mathrm{C}}$ is given by

$$
i_{\mathrm{C}}=i_{L}
$$

The relation between $v_{\mathrm{C}}$ and $v_{\text {in }}$ at a steady state can be derived from (3) and (4) as follows

$$
\frac{v_{\mathrm{c}}}{v_{\mathrm{in}}}=\frac{T_{\mathrm{nsh}}}{T_{\mathrm{nsh}}-T_{\mathrm{sh}}}
$$

where $T_{\mathrm{sh}}$ and $T_{\mathrm{nsh}}$ are time intervals for the ST and NST states, respectively, and $T_{\mathrm{s}}=T_{\mathrm{sh}}+T_{\mathrm{nsh}}$. From (7), $D_{\mathrm{sh}}\left(=T_{\mathrm{sh}} / T_{\mathrm{s}}\right)$ can be expressed as

$$
D_{\mathrm{sh}}=\frac{v_{\mathrm{C}}-v_{\text {in }}}{2 v_{\mathrm{C}}-v_{\text {in }}}
$$

To implement the ST operation, various PWM strategies have been introduced [15-19]. In this paper, the modified space vector modulation boost control (MSVMBC) is employed because the MSVMBC is based on the SVPWM which in turn is easy to implement in digital hardware and exhibits lower current harmonics [18]. However, it should be noted that the application of the proposed control strategy is not restricted by the choice of PWM strategies. Fig. $1 c$ shows the PWM patterns of MSVMBC.

\section{Proposed design strategy for the capacitor voltage control of the $\mathrm{ZSI}$}

\subsection{Average current model of the Z-network capacitor}

When the ZSI operates avoiding the unwanted modes, the peak dc-link voltage of the ZSI, $v_{\mathrm{dc}}$, during the NST state is determined by $v_{\text {in }}$ and $v_{\mathrm{C}}$ as follows

$$
v_{\mathrm{dc}}=2 v_{\mathrm{C}}-v_{\mathrm{in}}
$$

Hence, $v_{\mathrm{dc}}$ can be regulated through the control of $v_{\mathrm{C}}$ because $v_{\text {in }}$ can be regarded as an input variable; in this paper, the desired $v_{\mathrm{dc}}$ is obtained via the control of $v_{\mathrm{C}}$.

From (2), (5) and (6), the Z-network capacitor current over a switching period can be summarised as

$$
i_{\mathrm{C}}=\left\{\begin{array}{cc}
-i_{L} & \left(\text { during } T_{\mathrm{sh}}\right) \\
i_{L}-i_{\text {inv }} & \left(\text { during } T_{\mathrm{nsh} 1}\right) \\
i_{L} & \left(\text { during } T_{\mathrm{nsh} 0}\right)
\end{array}\right.
$$

where $T_{\text {nsh0 }}$ and $T_{\text {nsh1 }}$ represent time intervals for the zero voltage vectors and the effective voltage vectors over a switching period, respectively, during the NST state. Fig. 2 shows an example of waveforms of Z-network currents and an inverter dc-side current during a steady state, wherein the MSVMBC PWM, as shown in Fig. $1 c$, is adopted. It is seen from Fig. 2 that the average value of $i_{L}$ can be easily obtained by synchronising the sampling point of A/D converter to the top (or bottom) of the carrier signal for a PWM. In addition, the relation of the capacitor current in (10) is verified from Fig. 2.

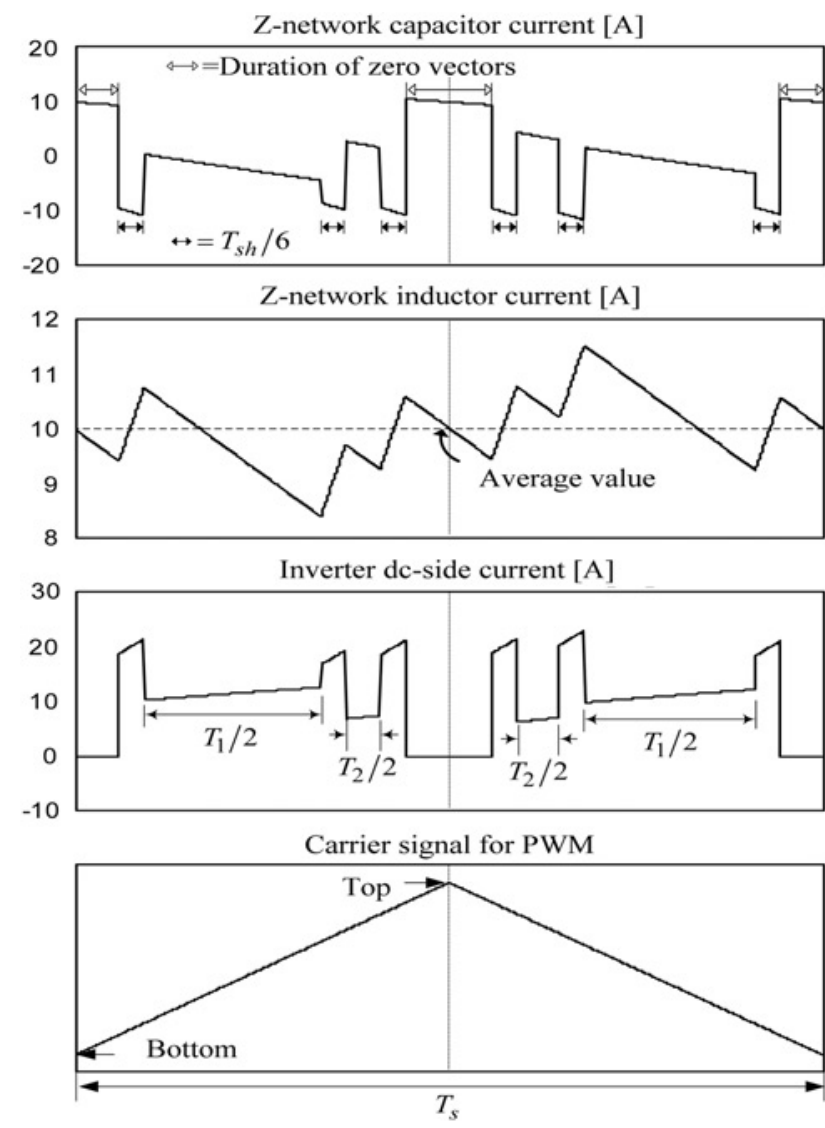

Fig. 2 Z-network currents and inverter dc-side current waveforms over a switching period during a steady state

From (10) and Fig. 2, the average capacitor current over a switching period, $i_{\mathrm{C} \_ \text {avg }}$, can be expressed as

$$
\begin{aligned}
i_{\text {C_avg }} & =-i_{L_{-} \text {avg }} \frac{T_{\text {sh }}}{T_{\mathrm{s}}}+i_{L \_ \text {avg }} \frac{T_{\text {nsh }}}{T_{\mathrm{s}}}-i_{\text {inv_avg }} \\
& =\left(1-2 D_{\text {sh }}\right) i_{L \_ \text {avg }}-i_{\text {inv_avg }}
\end{aligned}
$$

where $i_{L \_ \text {avg }}$ and $i_{\text {inv_avg }}$ are the average value of $i_{L}$ and $i_{\text {inv }}$ over a switching period, respectively, and $i_{\text {inv_avg }}$ can be estimated by using inverter phase currents, usually sensed for the inverter control and time intervals of effective voltage vectors [20,21].

In a steady state, substituting (8) into (11) yields

$$
i_{\mathrm{C} \_a v g}=\left(\frac{v_{\text {in }}}{2 v_{\mathrm{C}}-v_{\text {in }}}\right) i_{L \_a v g}-i_{\text {inv } \_ \text {avg }}
$$

It is seen from (12) that $i_{\mathrm{C}_{-} \text {avg }}$ is coupled with $i_{L_{-} \text {avg }}$ and $i_{\text {inv_avg. }}$. Generally, the inverter load current, denoted as $i_{\text {inv_avg }}$ in (12), is independently controlled regardless of the Z-network currents. Therefore assuming that $i_{\text {inv avg }}$ is decoupled from (12) using a feed-forward compensation, $i_{\text {C_avg }}$ can be indirectly controlled through the control of $i_{L_{-} \text {avg. }}$. The reference value for $i_{L_{\_} \text {avg }}$, $i^{*}{ }_{L}$ avg , can be obtained from (12) as follows

$$
i_{L_{-} \text {avg }}^{*}=\frac{\left(2 v_{\mathrm{C}}-v_{\text {in }}\right)\left(i_{\mathrm{C} \_ \text {avg }}^{*}+i_{\text {inv_avg }}\right)}{v_{\text {in }}}
$$

where $i^{*}{ }_{\mathrm{C} \_ \text {avg }}$ is the reference value for $i_{\mathrm{C} \_ \text {avg }}$. By regulating $i_{L_{-} \text {avg }}$ according to $i^{*}{ }_{L \_a v g}$ given by (13), $i_{\mathrm{C}_{-} \text {avg }}$ also can be controlled to be the same as $i^{*}{ }_{C_{\_} \text {avg. }}$. This concept is one of the main contributions of the paper; the capacitor voltage controller can be easily designed because the linearised transfer function for the 

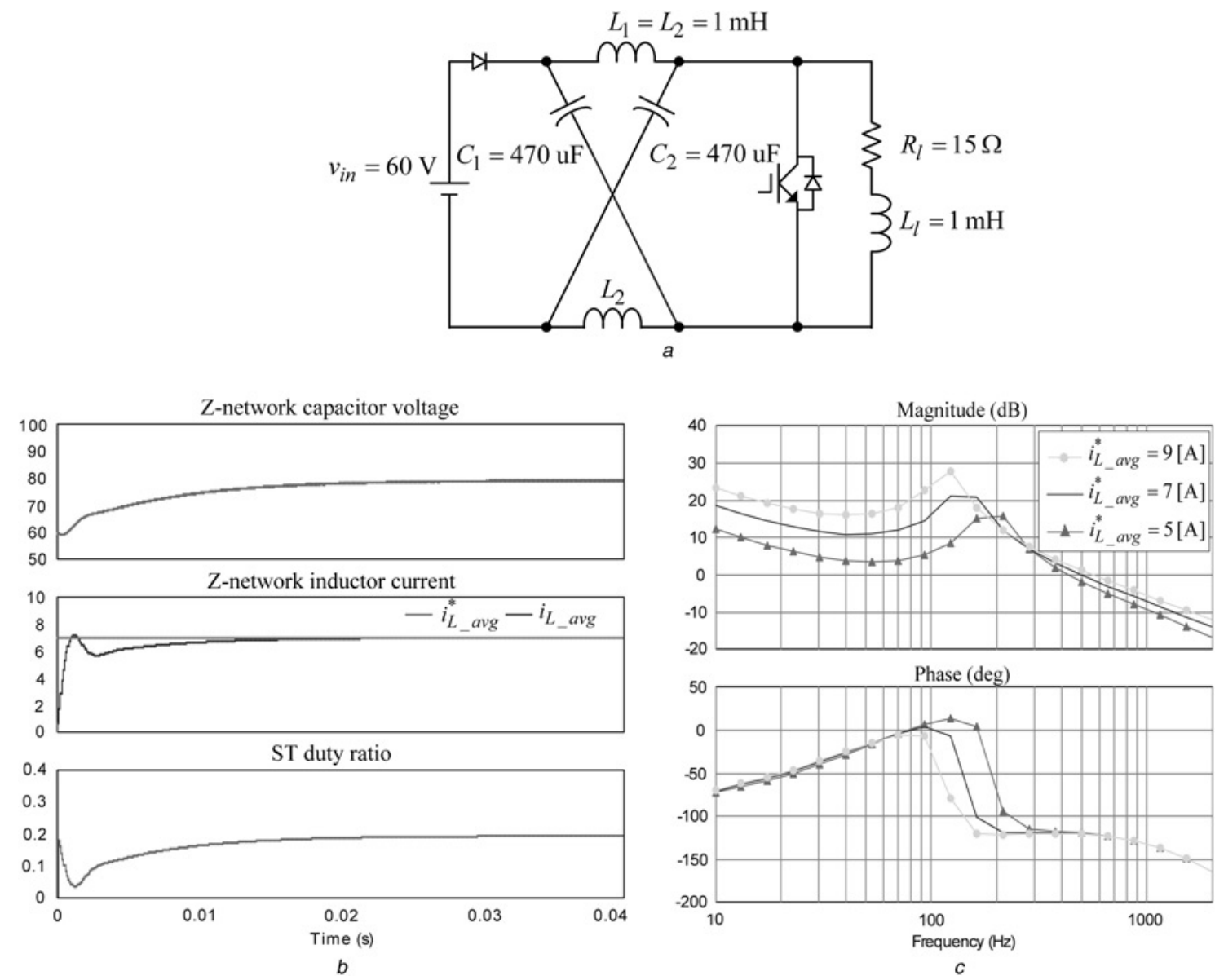

Fig. 3 Z-source converter circuit and simulation results of the Z-network current controller designed using small signal model

$a$ Z-source converter circuit

$b$ Step response of the Z-network inductor current controller designed using small signal models based method

$c$ Bode plots of the small signal models based current control loop according to the variation of operating points

capacitor voltage control, valid over entire operating range, is obtained through the proposed indirect capacitor current control concept. A detailed design strategy for the capacitor voltage control based on the proposed concept will be described in Section 3.4 .

\subsection{Problem statement of the small signal models based current control}

In the conventional current control method based on small signal models, control-to-inductor-current transfer function, used in designing the current controller, is obtained using steady state values of the state, input and output variables at the specific operating point. However, this transfer function does not represent exact dynamics over the entire operating range. Therefore the transient response of the conventional small signals based current controller does not exactly coincide with the designed goals such as bandwidth and phase margin. Fig. $3 b$ shows the simulation result of the Z-network inductor current control of the Z-source converter shown in Fig. $3 a$, wherein the current controller is designed using the conventional small signal models based method. The proportional and integral gains of the current controller satisfying the design goals (bandwidth $=3,141 \mathrm{rad} / \mathrm{s}$, phase margin $=60^{\circ}$ ) have been selected from the bode plot of the open-loop transfer function including the PI type current controller and the discretised control-to-inductor-current transfer function obtained from small signal models at the specific operating point $\left(v_{\text {in }}=60 \mathrm{~V}, i^{*} L_{-a v g}=7 \mathrm{~A}, T_{\mathrm{s}}=0.1 \mathrm{~ms}\right)$. In this way, the proportional and integral gains were set to 0.0138 and 9.12, respectively. Fig. $3 c$ shows the bode plots of the compensated current control loop according to the variation of operating points, wherein the gains of the PI current controller were fixed to the values obtained using the transfer function at $i^{*}{ }_{L \text { avg }}=7 \mathrm{~A}$. It is obvious from Fig. $3 c$ that the actual bandwidth of the current controller varies according to the operating point variation, and thus, the design goals (bandwidth $=3,141 \mathrm{rad} / \mathrm{s}$ ) cannot be satisfied as the operating point deviates from the specific operating point. The simulation result in Fig. $3 b$ shows a definite evidence that the performance of the current controller designed based on small signal models can be degraded because of a large deviation from the specific operating point. To cope with this problem, the average voltage based Z-network inductor current control is presented in this paper.

\subsection{Average voltage based current control of the Z-network inductor}

When the ZSI operates avoiding unwanted modes, the average voltage of the Z-network inductor over a switching period, $v_{L_{-} \text {avg }}$, can be derived from (3) and (4) as follows

$$
v_{L_{-} \text {avg }}=v_{\mathrm{C}} D_{\mathrm{sh}}+\left(v_{\mathrm{in}}-v_{\mathrm{C}}\right)\left(1-D_{\mathrm{sh}}\right)
$$

From (14), $D_{\text {sh }}$ is given by

$$
D_{\mathrm{sh}}=\frac{v_{L_{-a v g}}-v_{\text {in }}+v_{\mathrm{C}}}{2 v_{\mathrm{C}}-v_{\text {in }}}
$$

It can be seen from (15) that assuming $v_{\text {in }}$ and $v_{C}$ remain over a PWM period, the average voltage of the Z-network inductor can be exactly controlled by adjusting $D_{\text {sh }}$ according to (15). This means that the 
dynamics of the average current of the Z-network inductor can be described by a simple state space average model such as

$$
\frac{\mathrm{d} i_{L \_ \text {avg }}}{\mathrm{d} t}=\frac{v_{L_{-a v g}}}{L}
$$

It should be noted that (16) is a linear model in itself, and thus, a linearisation at the specific operating point is not necessary and performance enhancement in the current control is naturally expected when the current controller is designed on the basis of (16).

Let $k_{\mathrm{pc}}$ and $k_{\mathrm{ic}}$ are proportional and integral gains of the PI current controller, $L$ and $R$ are the inductance and equivalent series resistance (ESR) of the Z-network inductor, respectively, then the transfer function between $i^{*} L_{-}$avg and $i_{L_{-} \text {avg }}$ is given by

$$
\frac{i_{L \_\mathrm{avg}}}{i_{L_{-\mathrm{avg}}^{*}}^{*}}=\frac{k_{\mathrm{pc}} s+k_{\mathrm{ic}}}{L s^{2}+\left(k_{\mathrm{pc}}+R\right) s+k_{\mathrm{ic}}}
$$

and the $k_{\mathrm{pc}}$ and $k_{\mathrm{ic}}$ can be set based on the pole-zero cancellation technique as follows [22]

$$
k_{\mathrm{pc}}=L \omega_{\mathrm{cc}}, \quad k_{\mathrm{ic}}=R \omega_{\mathrm{cc}}
$$

where $\omega_{\mathrm{cc}}$ is the desired bandwidth of the current controller and the transfer function in (17) becomes a first-order low-pass filter with the bandwidth of $\omega_{\mathrm{cc}}$. Fig. 4 shows the simulation result of the Z-network inductor current control with the proposed method for the Z-source converter shown in Fig. $3 a$. The bandwidth of the current controller is set to $3,141 \mathrm{rad} / \mathrm{s}$ using (18). It can be seen that comparing Figs. $3 b$ and $4 a$, the proposed current control method shows a better transient response than the conventional small signal models based current control.

Fig. $4 b$ shows the bode plots of the compensated current control loop according to the variation of operating points, wherein the proposed current control strategy has been applied. It is obvious from Fig. $4 b$ that the proposed current control method shows a uniform performance which is insensitive to the operating-point variation (compared with Fig. 3c). Since the performance of the outer voltage control loop depends on the performance of the inner current controller, it is expected that the proposed current control scheme will contribute to the improvement of the voltage control capability at transient states.

\subsection{Average current based voltage control of the Z-network capacitor}

As described in Section 3.1, the average current of the Z-network capacitor can be indirectly controlled through the average current control of the Z-network inductor. From the proposed indirect capacitor current control concept, the voltage control system of the Z-network capacitor can be constructed as shown in Fig. $5 a$. The inner current control loop is usually set to have a higher bandwidth than the outer voltage control loop, and thus, the voltage and current control loop can be designed separately [22]. In Fig. $5 a$, the inner current control loop is implemented using the average voltage model of the Z-network inductor as described in Section 3.2. Owing to the higher bandwidth of the inner current control loop, the current control loop can be neglected in designing the voltage controller [22]; from this, the voltage control system of the Z-network capacitor can be simplified as shown in Fig. $5 b$. Based on the average voltage control of the Z-network inductor presented in Section 3.3, the closed loop system of the current control can be simplified as shown in Fig. $5 c$.

From Fig. $5 b$, the closed loop transfer function of the capacitor voltage control system is given by

$$
\frac{v_{\mathrm{C}}}{v_{\mathrm{C}}^{*}}=\frac{\left(k_{\mathrm{pv}} / C\right) s+\left(k_{\mathrm{iv}} / C\right)}{s^{2}+\left(k_{\mathrm{pv}} / C\right) s+\left(k_{\mathrm{iv}} / C\right)}
$$

where $k_{\mathrm{pv}}$ and $k_{\mathrm{iv}}$ are proportional and integral gains of PI type voltage controller, respectively, and $C$ is the capacitance of the Z-network capacitor. The PI type controller produces an overshoot with the step change of reference, thus an integral and proportional (IP) type controller is adopted as follows [22]

$$
i_{\mathrm{C}_{-} \mathrm{avg}}^{*}=-k_{\mathrm{pv}} v_{\mathrm{C}}+k_{\mathrm{iv}} \int\left(v_{\mathrm{C}}^{*}-v_{\mathrm{C}}\right) \mathrm{d} t
$$

When using the IP controller, the closed loop transfer function of the

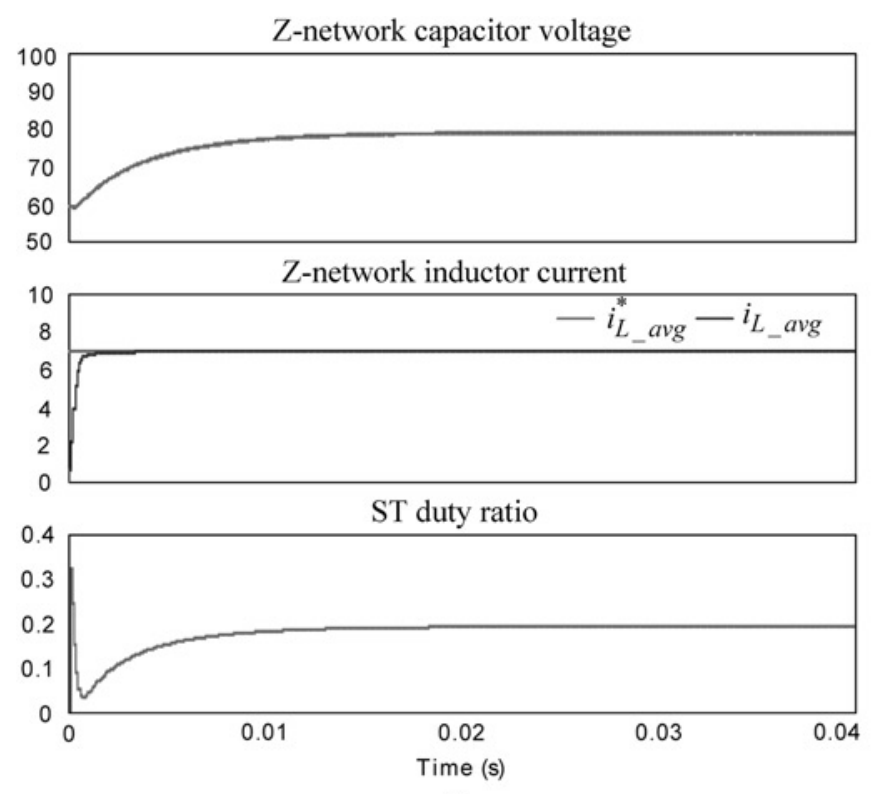

a

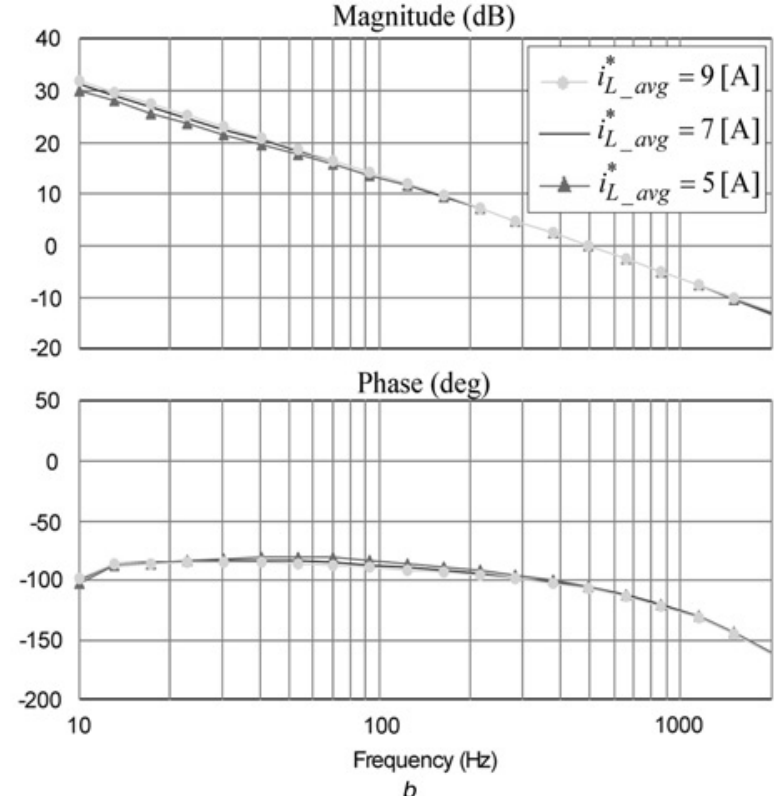

Fig. 4 Simulation result of the Z-network inductor current controller with the proposed method

$a$ Step response of the Z-network inductor current controller designed using the proposed method

$b$ Bode plots of the proposed current control loop according to the variation of operating points (to compare with the small signal model-based method shown in Fig. $3 c$ ) 

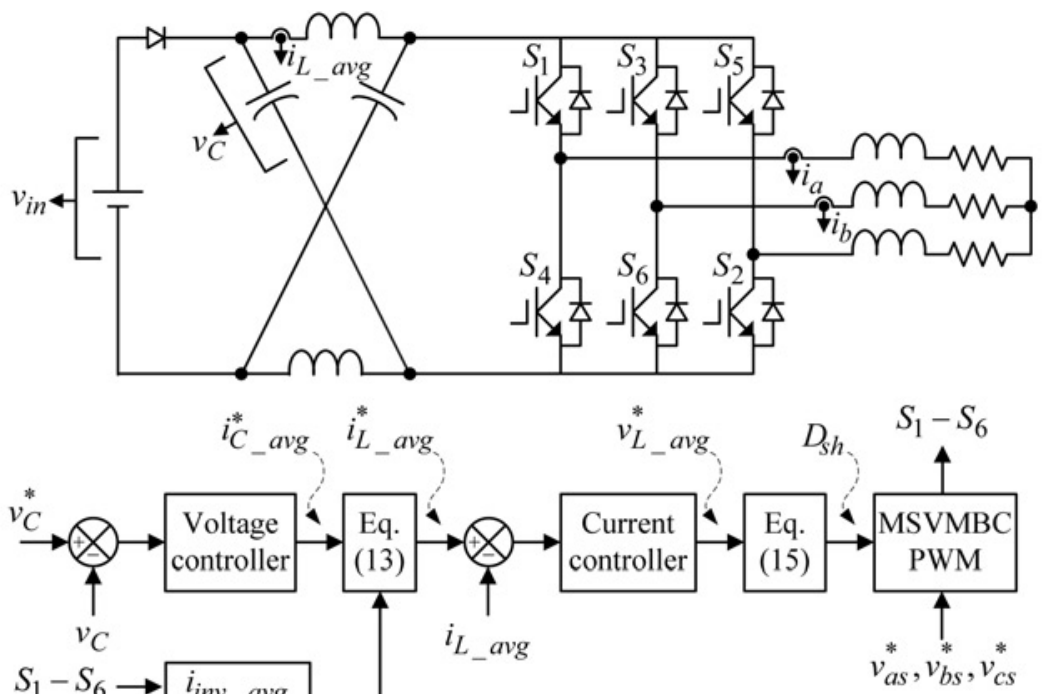

$$
i_{a}, i_{b} \rightarrow \text { estimator }
$$

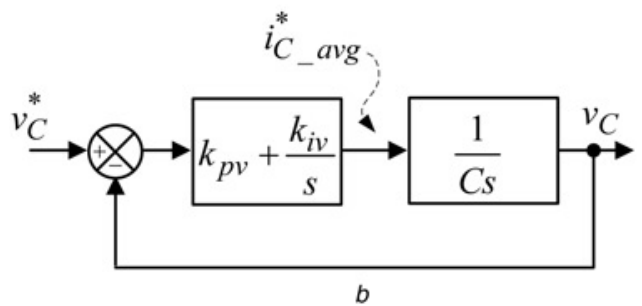

Fig. 5 Block diagram of the proposed voltage control system of the ZSI

$a$ Proposed voltage control system of the ZSI

$b$ Simplified voltage control system of the Z-network capacitor

$c$ Simplified current control system of the Z-network inductor

capacitor voltage control system is given by

$$
\frac{v_{\mathrm{C}}}{v_{\mathrm{C}}^{*}}=\frac{\left(k_{\mathrm{iv}} / C\right)}{s^{2}+\left(k_{\mathrm{pv}} / C\right) s+\left(k_{\mathrm{iv}} / C\right)}
$$

and the $k_{\mathrm{pv}}$ and $k_{\mathrm{iv}}$ can be selected based on the step response characteristics of a standard second-order system according to the variation of the damping ratio, $\zeta$ and the undamped natural frequency, $\omega_{\mathrm{n}}$. Then, the gains are given by

$$
k_{\mathrm{pv}}=2 C \zeta \omega_{\mathrm{n}}, \quad k_{\mathrm{iv}}=C \omega_{\mathrm{n}}^{2}
$$

\subsection{Comparison between the conventional small-signal model and the averaged model based controls}

The most of the conventional control strategies for the ZSI utilise a transfer function obtained from the small-signal model of the ZSI. It should be emphasised that the transfer function derived from the small-signal model is only valid at a given specific operating point because the values of the ST duty ratio, input voltage, capacitor voltage and inductor current at the specific operation point are used in the derived transfer function. The operating point of the ZSI changes according to the input voltage variation and the control purpose, and to minimise the losses of the ZSI, the dc-link voltage of the ZSI should be adjusted according to the required output voltage $[13,15]$. Therefore when the conventional small-signal model-based control for the ZSI is used, the gains of the inner current control loop and the outer voltage control loop should be changed according to the operating point variation to guarantee a stable operation at the transient-states. This will make the overall controller design process more complex and results in additional efforts for the tuning of the controller gains.
The proposed control strategy is based on the averaged model of the Z-network capacitor and inductor. The averaged model based control has been widely employed in the current control of the two-level inverter, however, there has been no effort to apply the averaged model based control for the ZSI. The main advantage of the averaged model based control is that the controller could be easily designed based on the well-known standard second-order system. In addition, the averaged model represents the dynamics of the ZSI regardless of the operating point variation. This means that the gains of the controller designed from the averaged model do not have to be changed according to the operating point variation. It can greatly reduce the tuning efforts which are generally required when using the small-signal model based control, and shows consistent transient responses over the entire operating ranges. To apply the averaged model based control for the ZSI, both the averaged current model of the Z-network capacitor and the averaged voltage model of the Z-network inductor have been derived in this paper.

\section{Simulation and experimental results}

Simulation and experimental studies were performed to prove the validity of the proposed control method for the ZSI whose parameters are listed in Table 1. An experimental setup was configured using a DSP controller with the TMS320F28335 and a 3-phase inverter. The Z-network inductor current and the Z-network capacitor voltage are sensed for the purpose of control. The output currents of the ZSI are also measured by two current sensors and used in controlling output currents of the ZSI. The MSVMBC is adopted for the PWM strategy of the ZSI and the PWM frequency is set to $10 \mathrm{kHz}$. The sampling points for the sensing of currents and voltages are synchronised with the top of 
Table 1 ZSI parameters

\begin{tabular}{lc}
\hline Variable name & Value \\
\hline inductance $\left(L_{1}, L_{2}\right)$ & $1 \mathrm{mH}$ \\
ESR of inductance $(R)$ & $0.1 \Omega$ \\
capacitance $\left(C_{1}, C_{2}\right)$ & $470 \mu \mathrm{F}$ \\
load resistance $\left(R_{\text {load }}\right)$ & $15 \Omega$ \\
load inductance $\left(L_{\text {load }}\right)$ & $1 \mathrm{mH}$ \\
input voltage $\left(V_{\text {in }}\right)$ & $60 \mathrm{~V}$ \\
\hline
\end{tabular}

the PWM carrier signal, which corresponds to the centre point of the zero vector applying period. This guarantees an average value sensing of the Z-network inductor and load currents. The control algorithm of the ZSI is implemented in the A/D converter-conversion-complete-interrupt-service-routine at every $100 \mu \mathrm{s}$.

Fig. $6 a$ shows the simulated step response of the Z-network current controller, wherein the proposed current control method has been implemented for the ZSI having the parameters listed in Table 1. The bandwidth of the Z-network current controller was set to $3,141 \mathrm{rad} / \mathrm{s}$ by using the PI gain-setting rules presented in (18): $k_{\mathrm{pc}}=3.141, k_{\mathrm{ic}}=314.1$ at the given condition. Fig. $6 b$ shows the bode plots of the proposed current control loop according to the operating points variation. As is the case at the Z-source converter in Section 3, it can be seen from Fig. $6 b$ that the proposed current control strategy shows the similar results also for the ZSI; the bandwidth of the compensated current control loop remains $3,141 \mathrm{rad} / \mathrm{s}$ regardless of the operating point variation.
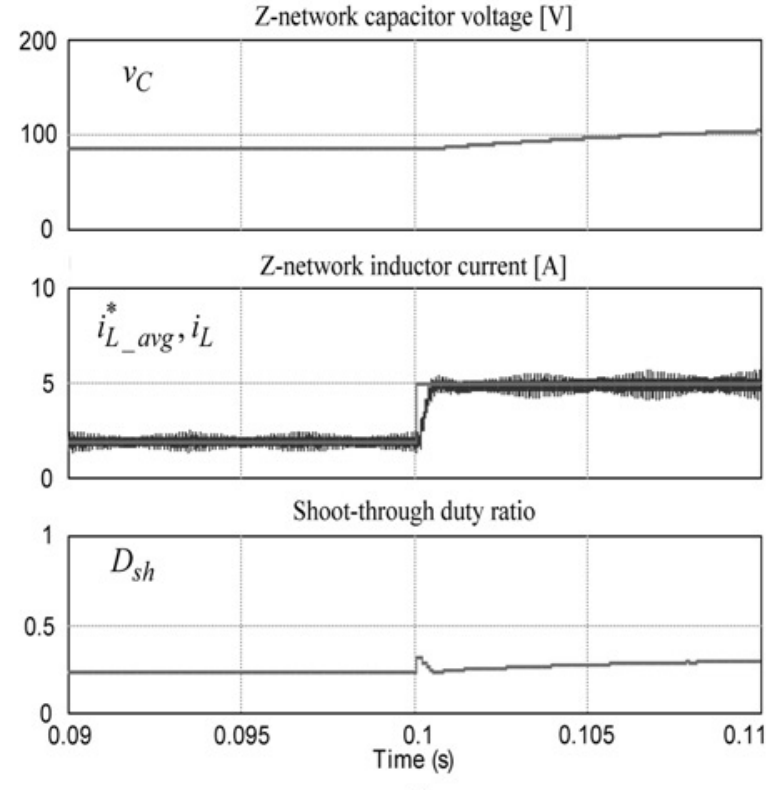

a

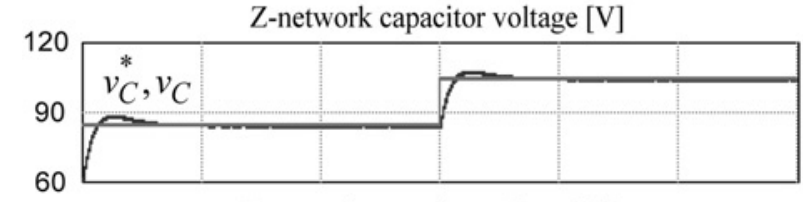

Z-network capacitor voltage [V]

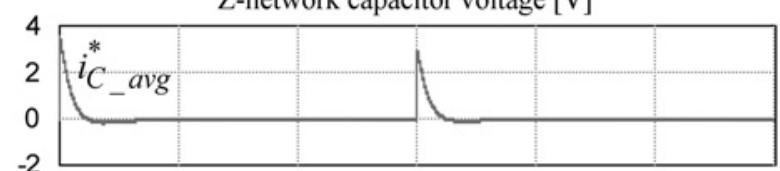

Reference for the Z-network inductor current [A]
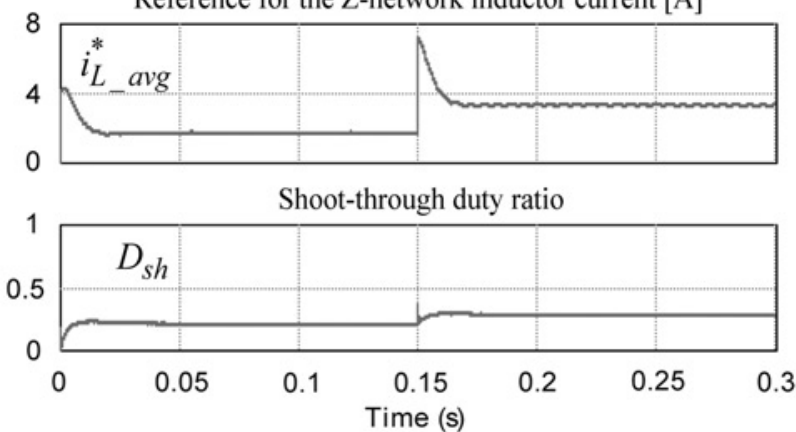

$c$

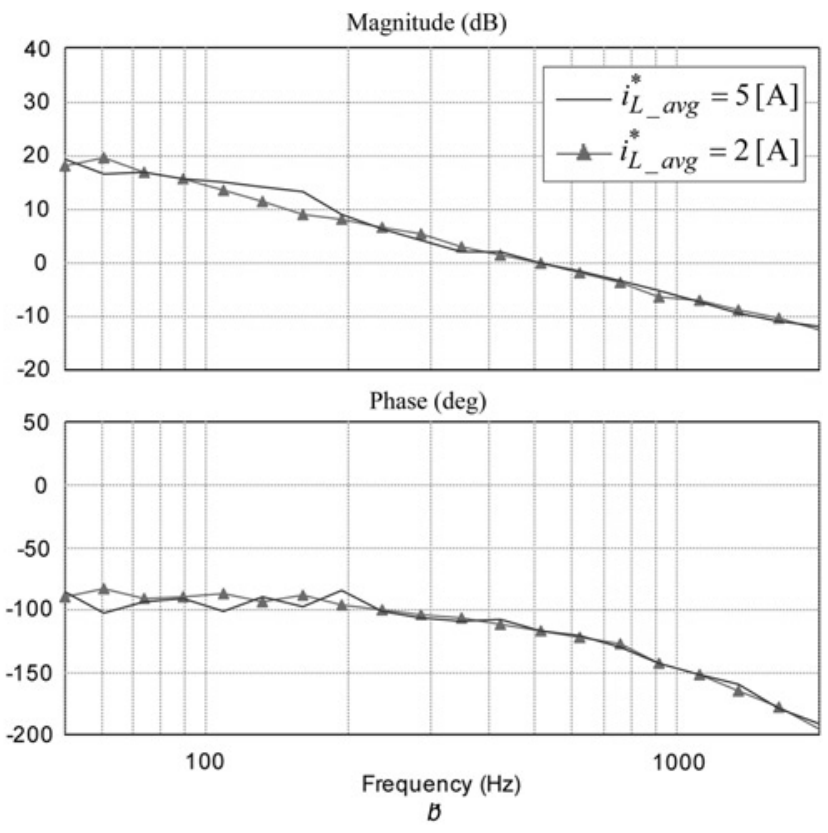

Z-network capacitor voltage [V]

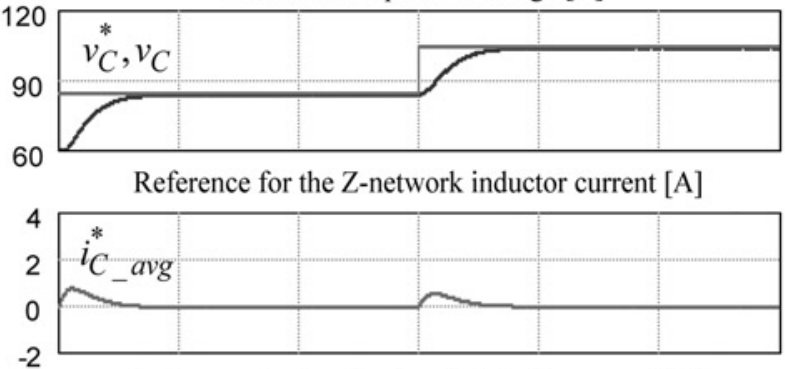

Reference for the Z-network inductor current [A]
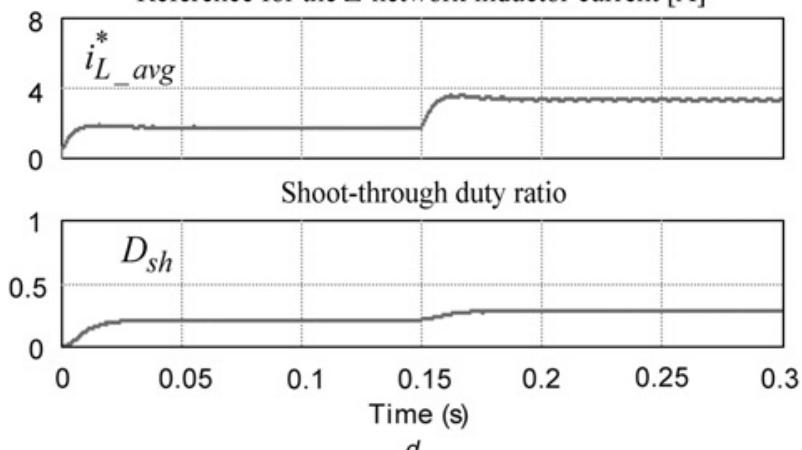

$d$

Fig. 6 Simulation results of the ZSI with the proposed control method

$a$ Step response of the Z-network inductor current controller designed using the proposed method $b$ Bode plots of the proposed current control loop according to the variation of operating points

$c$ Step response of the Z-network capacitor voltage controller using the PI controller

$d$ Step response of the Z-network capacitor voltage controller using the IP controller 

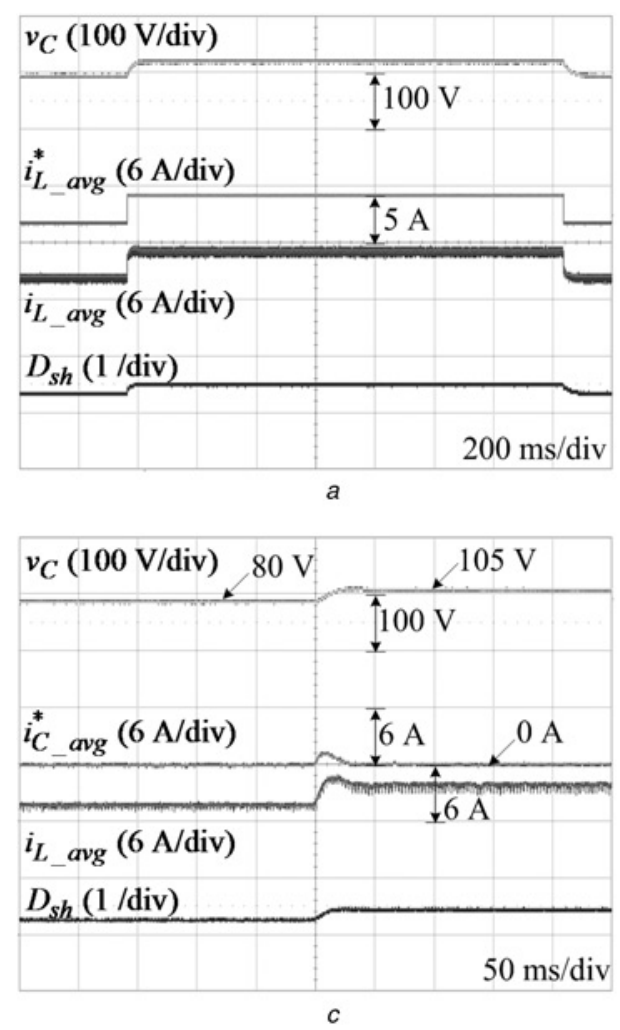
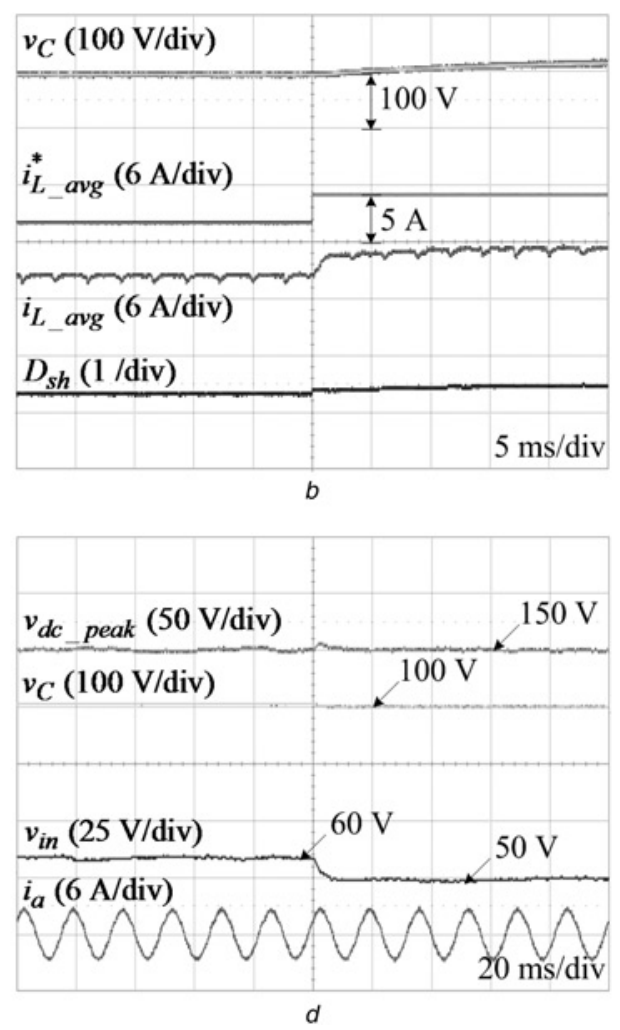

Fig. 7 Experimental results of the ZSI with the proposed control method $a$ Experimental waveform of the proposed current control $b$ Zoom-in waveform of Fig. $7 a$

$c$ Experimental waveform of the proposed Z-network capacitor voltage control

$d$ Experimental waveform of the peak dc-link voltage control of the ZSI based on the proposed capacitor voltage control

Figs. $6 c$ and $d$ show the simulation result of the proposed Z-network capacitor voltage controller, wherein the PI type and IP type voltage controller were used, respectively. The PI gains of the voltage controller were obtained from (22): $\zeta$ and $\omega_{\mathrm{n}}$ are set to 1 and $150 \mathrm{rad} / \mathrm{s}$, respectively. It is seen that comparing Figs. $6 c$ and $d$, the PI type voltage controller exhibits a little overshoot because of the differential term in the denominator of the transfer function given by (19) [22]; on the other hand, the IP type voltage controller shows a critical damping characteristic as shown in Fig. $6 d$.

Figs. $7 a$ and $b$ show the experimental results of the Z-network inductor current control with the proposed method; the bandwidth of the current controller was set to $3,141 \mathrm{rad} / \mathrm{s}$. In Fig. $7 a$, the reference value of the Z-network inductor was changed from 2 to $5 \mathrm{~A}$ and vice versa. In the proposed control method of the Z-network inductor current, the closed loop transfer function between $i^{*}{ }_{L \text { avg }}$ and $i_{L_{-} \text {avg }}$ becomes a first-order low-pass filter, and thus, the transient response of the Z-network inductor current can be estimated from the bandwidth of the filter. When the bandwidth is set to $3,141 \mathrm{rad} / \mathrm{s}$, the electrical time constant $(\tau)$ becomes $0.318 \mathrm{~ms}$. Considering the characteristics of the first-order low-pass filter, the output of the filter almost reaches at its final value within $4 \tau$ [23]: $4 \tau=1.27 \mathrm{~ms}$ at the given condition. It can be seen from Fig. $7 b$ that the transient response of the proposed current control strategy exactly coincides with the designed bandwidth. It should be also noted from Figs. $7 a$ and $b$ that the capacitor voltage varies according to the Z-network inductor current, meaning that the proposed current control strategy shows satisfactory control performance even though the operating point of the ZSI is not fixed at the specific point. In other words, it can be stated that the proposed current control method is not affected by the operating point variation.

Fig. $7 c$ shows the experimental results of the proposed capacitor voltage control; the IP type controller was used for the voltage control. The gains of the voltage controller were obtained from
(22): $\zeta$ and $\omega_{\mathrm{n}}$ are set to 1 and $150 \mathrm{rad} / \mathrm{s}$, respectively. In a standard second-order system with a critical damping $(\zeta=1)$, the step response, $c(t)$, is given by Ogata [23]

$$
c(t)=1-\mathrm{e}^{-\omega_{\mathrm{n}} t}\left(1+\omega_{\mathrm{n}} t\right)
$$

From (23), it can be seen that the step response at $t=4 / \omega_{\mathrm{n}}$ reaches $90.84[\%]$ of the final value: $4 / \omega_{\mathrm{n}}=26.7 \mathrm{~ms}$ at the given condition. Experimental results shown in Fig. $7 c$ verify that the transient response of the proposed capacitor voltage control is nearly the same as the designed value. Fig. $7 d$ presents experimental results of the peak dc-link voltage control of the ZSI. The peak dc-link voltage control has been implemented on the basis of the proposed capacitor voltage control. The reference value of the capacitor voltage is obtained from the relation, $v_{\mathrm{dc}}=2 v_{\mathrm{C}}-v_{\text {in }}$ and the peak dc-link voltage is regulated through the control of the capacitor voltage. To examine the performance of the peak dc-link voltage control, the input voltage $\left(v_{\text {in }}\right)$ is abruptly changed from 60 to 50 $\mathrm{V}$, as shown in Fig. $7 d$. It can be seen from Fig. $7 d$ that the peak dc-link voltage is regulated to a desired value regardless of the input voltage variation by the proposed capacitor voltage control. Therefore it can be stated that although there is a non-linear relation between the peak dc-link voltage and the capacitor voltage in the ZSI [13], the peak dc-link voltage can be properly regulated by the proposed capacitor voltage control.

In the proposed Z-network capacitor voltage control method, the inverter load current estimated from inverter phase currents and time intervals of the effective voltage applying periods is used to calculate the reference value of the Z-network inductor current as shown in (13), and thus, the voltage control performance can be affected by the inverter load current estimation. It is seen from Fig. 8 that the estimation of the inverter load current is satisfactory; in Fig. 8, $T_{1}$ and $T_{2}$ represent the time intervals of the first and second effective voltage vectors over a switching period. 


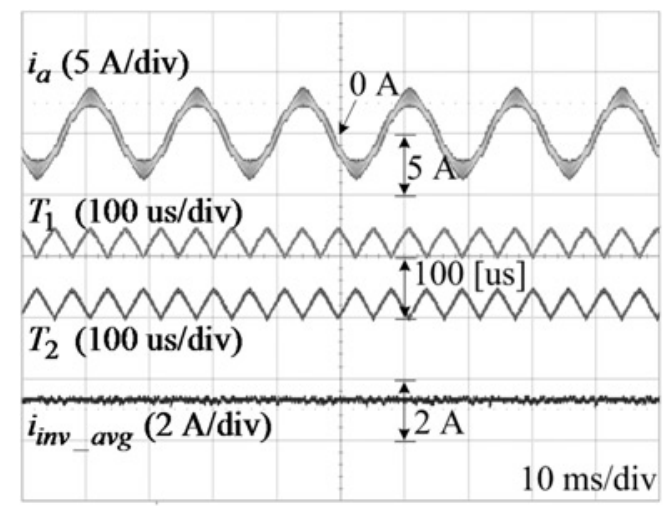

Fig. 8 Experimental result of the inverter load current estimation

\section{Conclusion}

This paper presented a novel design strategy for the capacitor voltage control of the ZSI. The average current model of the Z-network capacitor has been derived to verify that the capacitor current can be indirectly controlled through the Z-network inductor current. Based on the indirect capacitor current control concept, the linearised transfer function for the capacitor voltage control has been obtained and it has greatly simplified the design of the capacitor voltage control. The average voltage model of the Z-network inductor has been introduced to directly control the average inductor voltage through the shoot-through duty ratio. In addition, the linearised inductor-voltage-to-inductor-current transfer function, valid over the entire operating range except for the unwanted modes, has been utilised in implementing the Z-network inductor current controller on the basis of the average voltage model of the Z-network inductor. The simulation and experimental results have confirmed that the transient response of the Z-network can be precisely controlled through the proposed control method. The greatest advantage of the proposed method is that the control performance is not affected by the operating point variation unlike the conventional small-signal model-based control. Furthermore, the complex small signal models are not required for the proposed control, and thus, the whole design process of the proposed control is greatly simplified compared with the conventional small-signal model-based control. It should be also noted that the proposed method can be applied to various PWM strategies for the ZSI without modification of the control structure. The basic idea presented in this paper can be extended to the digital dual-loop control of the conventional DC-DC converters.

\section{References}

1 Peng, F.Z.: 'Z-source inverter', IEEE Trans. Ind. Appl., 2003, 39, (2), pp. 504-510

2 Peng, F.Z., Joseph, A., Wang, J., et al.: 'Z-source inverter for motor drives', IEEE Trans. Power Electron., 2005, 20, (4), pp. 857-863

3 Huang, Y., Shen, M., Peng, F.Z., Wang, J.: 'Z-source inverter for residential photovoltaic systems', IEEE Trans. Power Electron., 2006, 21, (6), pp. 1776-1782

4 Hanif, M., Basu, M., Gaughan, K.: 'Understanding the operation of a Z-source inverter for photovoltaic application with a design example', IET Power Electron., 2011, 4, (3), pp. 278-287

5 Liu, Y., Ge, B., Abu-Rub, H., Peng, F.Z.: 'Modelling and controller design of quasi-Z-source inverter with battery-based photovoltaic power system', IET Power Electron., 2014, 7, (7), pp. 1665-1674

6 Siwakoti, Y.P., Blaabjerg, F., Loh, P.C., Town, G.E.: 'High-voltage boos quasi-Z-source isolated DC/DC converter', IET Power Electron., 2014, 7, (9), pp. 2387-2395

7 Shen, M., Joseph, A., Wang, J., Peng, F.Z., Adams, D.J.: 'Comparison of traditional inverters and Z-source inverter for fuel cell vehicles', IEEE Trans. Power Electron., 2007, 22, (4), pp. 1453-1463

8 Shen, M., Peng, F.Z.: 'Operation modes and characteristics of the $Z$ source inverter with small inductance or low power factor', IEEE Trans. Ind. Electron., 2008, 55, (1), pp. 89-96

9 Rajakaruna, S., Jayawickrama, L.: 'Steady-state analysis and designing impedance network of Z-source inverters', IEEE Trans. Ind. Electron., 2010, 57, (7), pp. 2483-2491

10 Loh, P.C., Vilathgamuwa, D.M., Gajanayake, C.J., Lim, Y.R., Teo, C.W.: 'Transient modeling and analysis of pulse-width modulated $\mathrm{Z}$ source inverter', IEEE Trans. Power Electron., 2007, 22, (2), pp. 498-507

11 Liu, J., Hu, J., Xu, L.: 'Dynamic modeling and analysis of $\mathrm{Z}$ source converter-derivation of AC small signal model and design-oriented analysis', IEEE Trans. Power Electron., 2007, 22, (5), pp. 1786-1796

12 Galigekere, V.P., Kazimierczuk, M.K.: 'Small-signal modeling of PWM Z-source converter by circuit-averaging technique', IEEE Int. Symp. Circuits Syst., 2011, pp. 1600-1603

13 Ellabban, O., VanMierlo, J., Lataire, P.: 'A DSP-based dual-loop peak dc-link voltage control strategy of the Z-source inverter', IEEE Trans. Power Electron., 2012, 29, (9), pp. 4088-4097

14 Liu, H., Liu, P., Zhang, Y.: 'Design and digital implementation of voltage and current mode control for the quasi-Z-source converters', IET Power Electron., 2013, 6, (6), pp. 990-998

15 Shen, M., Wang, J., Joseph, A., et al.: 'Constant boost control of the Z-source inverter to minimize current ripple and voltage stress', IEEE Trans. Ind. Appl., 2006, 42, (3), pp. 770-778

16 Peng, F.Z., Shen, M., Qian, Z.: 'Maximum boost control of the Z-source inverter', IEEE Trans. Power Electron., 2005, 20, (4), pp. 833-838

17 Liu, Y., Ge, B., Abu-Rub, H.: 'Theoretical and experimental evaluation of four space vector modulations applied to quasi-Z-source inverters', IET Power Electron., 2013, 6, (7), pp. 1257-1269

18 Tran, Q.V., Chun, T.W., Ahn, J.R., Lee, H.H.: 'Algorithms for controlling both the DC boost and ac output voltage of Z-source inverter', IEEE Trans. Ind. Electron., $2007, \mathbf{5 4},(5)$, pp. $2745-2750$

19 Loh, P.C., Vilathgamuwa, D.M., Lai, Y.S., Chua, G.T., Li, Y.: 'Pulsewidth modulation of Z-source inverters', IEEE Trans. Power Electron., 2005, 20, (6), pp. 1346-1355

20 Lee, D.C., Lim, D.S.: 'AC voltage and current sensorless control of three-phase PWM rectifiers', IEEE Trans. Power Electron., 2002, 17, (6), pp. 883-890

21 Ha, J.I.: 'Voltage injection method for three-phase current reconstruction in PWM inverters using a single sensor', IEEE Trans. Power Electron., 2009, 24, (3), pp. 767-775

22 Sul, S.K.: 'Control of electric machine drive systems' (John Wiley \& Sons, 2011)

23 Ogata, K.: 'Modern control engineering' (Prentice Hall, 2010) 